\title{
социолОГИЯ
}

DOI: $10.17805 /$ ggz.2018.3.6

\section{Представления молодежи Москвы о гендерных ролях и характеристиках современной женщины}

Д. А. Тихомиров, К. В. Новиикая

Российский экономический университет им. Г. В. Плеханова, г. Москва

В статье на основании результатов проведенного в 2017 г. сочиологического исследования рассматриваются представления молодежи о гендерных ролях и характеристиках женщины, ключевых показателях ее успешности. В рамках тезаурусного подхода анализируются различия во взглядах молодого поколения с точки зрения половозрастных и религиозных характеристик. Показывается размывание традиционных представлений в различных группах молодежи, включая религиозную, что находит отражение в гендерной идентичности, ролях и связанных с ними характеристиках.

Ключевые слова: жизненные приоритеты; образ успешной женщины; гендерная идентичность; маскулинные характеристики; фемининные характеристики; молодежь; московская молодежь; религия; тезаурусный подход

\section{Moscow Youth's Representations of Gender Roles and Characteristics of a Modern Woman}

\author{
D. A. Tikhomirov, K. V. Novitskaya \\ Plekhanov Russian Economic University, Moscow
}

This article examines opinions of Moscow youth regarding women's gender roles and characteristics, key indicators of their success with reference to the results of a sociological study conducted in 2017. Within the thesaurus approach, the authors analyze differences in the views of the younger generation in terms of age, gender and religious characteristics. It is shown that the erosion of traditional representations in various groups of young people, including religious ones. This is reflected in gender identity, roles and related characteristics.

Keywords: life priorities; image of a successful woman; gender identity; masculine characteristics; feminine characteristics; youth; Moscow youth; religion; thesaurus approach 


\section{ВВЕДЕНИЕ}

Либерализация половой морали, развертывающаяся в странах Запада (Тихомиров, 2015), затронула и Россию, размыв основы многих традиционных ценностей, норм и установок (Тихомиров, 2017), что привело не только к ослаблению социальной регуляции поведения индивидов в семейно-брачной сфере, но и к изменению представлений о мужчине и женщине, их социальных ролях и гендерных характеристиках. Столкновение традиционных и либеральных идей находит свое отражение в тезаурусах (Луков В., Луков Вл., $2008,2013)$ молодого поколения, определяя перемены в их структурных элементах, в том числе и в гендерной идентичности, которая становится все менее целостной и определенной.

Трансформируется идентичность как мужчин, так и главным образом женщин, поскольку обозначенная либерализация в большей степени затрагивает последних, освобождая их от различных социальных пут, накладываемых социальными структурами. Женщины получают все большую свободу выбора жизненного пути, расширяется горизонт возможностей их самореализации, однако открывающиеся перспективы несут и новые риски усиления ролевого конфликта, оказывая негативное влияние на социальные институты семьи и брака. Неопределенность в выборе ролевых позиций актуализирует проблему гендерной идентичности женщины, проявляющуюся в противоречивом сочетании ролей и гендерных характеристик. Отражение данной проблемы в сознании молодого поколения мы и покажем на основании материалов проведенного эмпирического исследования. Другим аспектом нашего анализа стала способность религии выступать защитным механизмом тезауруса, подкрепляюшим традиционные ценностно-нормативные структуры, поддерживая его стабильность. В раскрытии обозначенных тем и видится цель данной статьи.

\section{МЕТОДЫ И МЕТОДОЛОГИЯ ИССЛЕДОВАНИЯ}

В качестве теоретико-методологического аспекта изучения данной проблемы используется тезаурусный подход (Луков В., Луков Вл., 2008, 2013; Луков, 2018), основанный на субъектной организации гуманитарного знания, позволяющий объяснить присутствие в сознание молодого поколения на первый взгляд парадоксальных представлений, в том числе сохранение и воспроизводство некоторых традиционных представлений одновременно с либеральными. Изучение идентичности предполагает использование прежде всего качественной стратегии социологического исследования. Однако перед основным качественным исследованием, которое еще впереди, мы провели пробное, включающее в себя метод неоконченных предложений и онлайнанкетирование. 
Метод неоконченных предложений позволил получить определенные материалы по двум ключевым аспектам для размещения соответствующих вопросов в анкете. Выборка строилась по принципу доступности и составила 80 студентов четырех групп 1-4 курсов РЭУ им. Г. В. Плеханова (36 \% юношей, 64 \% девушек).

Онлайн-анкетирование охватило 300 московских молодых людей в возрасте 18-29 лет (28 \% мужчин, 72 \% женщин). Внутри этой когорты были выделены две возрастные группы: 18-24-летних и 25-29-летних. Если первая из них в основном связана с получением образования и поисками своей профессиональной ниши, то вторая - с построением карьеры и созданием семьи. Выборка строилась при помощи метода снежного кома, первоначальным элементом которой выступила студенческая группа 4 курса РЭУ им. Г. В. Плеханова. Молодежь как объект исследования выбрана не случайно, поскольку проблемы идентичности этой группы оказывают наибольшее влияние на семейно-брачную сферу и демографическое будущее страны. Столичный мегаполис стал полем эмпирического анализа, так как в нем сконцентрировано наибольшее количество вузов и обучающихся в них студентов, представляющих различные регионы страны, что делает Москву центром не только диалога культур, но и культурных изменений.

Заметим проявленный интерес, который вызвала данная тема исследования у респондентов. Мы получили несколько письменных комментариев по электронной почте и в социальной сети «ВКонтакте» от женщин, принявших участие в опросе. В высказываниях подчеркивались не только актуальность темы исследования и интересные аспекты, затронутые в анкете, но и ее недостатки, связанные прежде всего с преобладанием традиционного мужского взгляда на женщину, ее ролях и гендерных характеристиках, что нашло отражение в соответствующих вопросах и предложенных на них ответах. Нас обвиняли в сексизме, «однобокой маскулинной позиции», непонимании жизненного мира женщины и ее проблем. Подобная реакция респондентов свидетельствует о распространении в молодежной среде феминистских взглядов, подтверждая изменения, происходящие в тезаурусах молодого поколения. К слову, тема феминизма все чаще привлекает внимание студентов в качестве предмета анализа научно-исследовательских социологических проектов, проводимых в РЭУ им. Г. В. Плеханова под руководством Д. А. Тихомирова.

Перейдем к рассмотрению основных результатов исследования.

\section{ПРЕДСТАВЛЕНИЯ МОЛОДЕЖИ О ЖИЗНЕННЫХ ПРИОРИТЕТАХ ЖЕНЩИНЫ}

В представлении молодежи о жизненных приоритетах женщины прослеживается сочетание традиционных и либеральных взглядов. Семья, хотя и 
остается на вершине иерархии, конкурирует с саморазвитием, которое становится одним из главных жизненных приоритетов. Ключевые позиции, имеющие некоторые различия по гендерному основанию, занимают любовь и здоровье (табл. 1).

Таблица 1. Жизненные приоритеты женщины в представлении молодых мужчин и женщин, \%

\begin{tabular}{|l|c|c|}
\hline \multirow{2}{*}{ Жизненные приоритеты женщины } & \multicolumn{2}{|c|}{ Пол } \\
\cline { 2 - 3 } & Мужской & Женский \\
\hline Любовь & 38 & 49 \\
\hline Семья & 64 & 58 \\
\hline Дети & 18 & 28 \\
\hline Карьера & 18 & 19 \\
\hline Здоровье & 44 & 32 \\
\hline Саморазвитие & 45 & 46 \\
\hline Совершенствование мира & 14 & 3 \\
\hline Путешествия & 9 & 21 \\
\hline Общественное признание & 13 & 5 \\
\hline Материальное благополучие & 14 & 23 \\
\hline
\end{tabular}

По мере взросления и приобретения жизненного опыта представления молодежи меняются. В старшей возрастной группе молодежи на первый план в иерархии жизненных приоритетов выходит здоровье, опережая даже семью (табл. 2). В чем же причина этого? Нам представляется, что это связано как с общим (не самым лучшим) состоянием здоровья молодого поколения, так и с последствиями пропаганды здорового образа жизни.

В представлениях различных возрастных групп заметны существенные гендерные отличия. Мнение мужчин о том, что важно в жизни для женщины, по ряду позиций серьезно расходится с мнением самих женщин, особенно это касается детей, карьеры и путешествий. Дети и путешествия для женщин гораздо более значимы, нежели считают мужчины, а карьера наоборот. С возрастом для женщин в той или иной степени уменьшается значение любви, саморазвития и карьеры, при этом повышается значение здоровья, детей и материального благополучия. 
Таблица 2. Жизненные приоритеты женщины в представлении различных возрастных групп молодых мужчин и женщчин, \%

\begin{tabular}{|l|c|c|c|c|}
\hline \multirow{2}{*}{$\begin{array}{c}\text { Жизненные приоритеты } \\
\text { женщины }\end{array}$} & \multicolumn{2}{c|}{$\mathbf{1 8 - 2 4}$ года } & \multicolumn{2}{c|}{ 25-29 лет } \\
\cline { 2 - 5 } & Мужчины & Женщины & Мужчины & Женщины \\
\hline Любовь & 39 & 52 & 36 & 30 \\
\hline Семья & 68 & 60 & 45 & 48 \\
\hline Дети & 18 & 17 & 18 & 38 \\
\hline Карьера & 14 & 20 & 36 & 9 \\
\hline Здоровье & 39 & 29 & 64 & 52 \\
\hline Саморазвитие & 45 & 48 & 45 & 35 \\
\hline Совершенствование мира & 16 & 2 & 9 & 9 \\
\hline Путешествия & 11 & 20 & 3 & 26 \\
\hline Общественное признание & 16 & 5 & 1 & 4 \\
\hline Материальное благополучие & 11 & 21 & 27 & 35 \\
\hline
\end{tabular}

Религиозный фактор оказывает свое влияние на представление молодежи о жизненных приоритетах современной женщины. Отличия по ряду категорий прослеживаются между полами внутри религиозных и неверующих групп молодежи, но наиболее сильные расхождения заметны в представлениях религиозных и неверующих женщин (табл. 3). Если для первых главным жизненным приоритетом является семья, то для вторых - саморазвитие, хотя и семья тоже важна, что в свою очередь может выступать основой для ролевой напряженности и конфликтов. Отметим почти двукратные различия между этими группами по таким категориям, как дети, здоровье, путешествия и материальное благополучие. Религиозные женщины сохраняют более традиционные взгляды, нежели неверующие, что находит отражение и в образе успешной женщины.

Таблица 3. Жизненные приоритеты женщины в представлении религиозных и неверующзих молодых мужчин и женщци, \%

\begin{tabular}{|l|c|c|c|c|}
\hline \multirow{2}{*}{$\begin{array}{c}\text { Жизненные приоритеты } \\
\text { женины }\end{array}$} & \multicolumn{2}{c|}{ Религиозные } & \multicolumn{2}{c|}{ Неверующие } \\
\cline { 2 - 5 } Любовь & Мужчины & Женщины & Мужчины & Женщины \\
\hline Семья & 47 & 53 & 33 & 44 \\
\hline Дети & 67 & 65 & 53 & 52 \\
\hline Карьера & 20 & 28 & 7 & 13 \\
\hline Здоровье & 17 & 20 & 20 & 20 \\
\hline Саморазвитие & 43 & 32 & 47 & 16 \\
\hline Совершенствование мира & 27 & 36 & 80 & 60 \\
\hline
\end{tabular}




\begin{tabular}{|l|c|c|c|c|}
\hline Путешествия & 10 & 17 & 3 & 32 \\
\hline Общественное признание & 17 & 5 & 7 & 4 \\
\hline Материальное благополучие & 17 & 23 & 13 & 40 \\
\hline
\end{tabular}

\section{ОБРАЗ УСПЕШНОЙ ЖЕНЩИНЫ}

Опишем образ успешной женщины в представлении молодого поколения. Для определения основных признаков успешности женщины в восприятии молодежи и последующего формулирования вариантов ответа на соответствующий вопрос анкеты мы использовали метод неоконченных предложений. Респонденты ( $\mathrm{N}=80$ студентов) продолжали следующее предложение: «Современная женщина считается успешной, если у нее есть... (не более трех признаков)». В результате были получены различные оценки респондентов успешности женщины (любовь, любимый, любимый мужчина, муж, ребенок, дети, много детей, семья, друзья, деньги, материальное благополучие, материальный достаток, богатство, высокий доход, статус, хорошая, престижная работа, высокая, руководящая должность, успешная карьера, свой бизнес, известность, уважение, признание, много подписчиков и т. д.), которые мы обобщили, выделив пять групп признаков (муж, дети, высокий доход, профессиональные достижения и общественное признание). Отметим, что само понятие «успех» применяется молодыми людьми как к мужчинам, так и к женщинам, но его наполнение в гендерном аспекте значительно отличается. Мужчины связывают успешность женщины в первую очередь с ее семейными ролями, а женщины - с профессиональными, т. е. здесь проявляется столкновение традиционных и либеральных взглядов на положение женщины в обществе. Проиллюстрируем это, используя материалы проведенного анкетирования. Ровно половина (50 \%) опрошенных женщин связывают успешность женщины с ее профессиональными достижениями, а среди мужчин эту точку зрения разделяют 37 \%. Ключевыми показателями женского успеха в восприятии мужчин являются наличие у нее мужа (52 \%) и детей (59\%), тогда как сами женщины придают им гораздо меньшее значение: $34 \%$ и $38 \%$ соответственно (табл. 4). 
Таблица 4. Признаки успешности женщины в представлении молодых мужчин и женщзин, \%

\begin{tabular}{|l|c|c|}
\hline \multirow{2}{*}{ Признаки успешности женщины } & \multicolumn{2}{|c|}{ Пол } \\
\cline { 2 - 3 } & Мужской & Женский \\
\hline Муж & 52 & 34 \\
\hline Дети & 59 & 38 \\
\hline Высокий доход & 13 & 26 \\
\hline Профессиональные достижения & 37 & 50 \\
\hline Общественное признание & 15 & 9 \\
\hline Затрудняюсь ответить & 15 & 15 \\
\hline
\end{tabular}

Значимым основанием дифференциации восприятия образа успешной женщины выступает не только гендерный, но и религиозный фактор. Различия, высвечивающие представление о социальном положении и ролях современной женщины, проходят не только между группами религиозных и неверующих молодых людей, но и между представителями противоположных полов внутри этих групп. Молодые люди, причисляющие себя к определенной религии, в большей степени по сравнению с неверующими придерживаются традиционных взглядов, особенно это характерно для мужчин, которые успех женщины в основном сводят к семейным ролям. Позиция религиозных женщин менее определенная, что выражается в совмещении профессиональных и семейных ролей. Такая неоднозначная позиция религиозных женщин существенно отличается как от традиционных взглядов религиозных мужчин, так и от либеральной позиции неверующих мужчин и особенно женщин, отдающих явный приоритет профессиональным ролям женщины в качестве ключевых показателей ее успешности (табл. 5).

Таблища 5. Признаки успешности женщины в представлении религиозных и неверующих молодых мужчин и женщин, \%

\begin{tabular}{|l|c|c|c|c|}
\hline \multirow{2}{*}{$\begin{array}{c}\text { Признаки успешности жен- } \\
\text { щины }\end{array}$} & \multicolumn{2}{|c|}{ Религиозные } & \multicolumn{2}{c|}{ Неверующие } \\
\cline { 2 - 5 } & Мужчины & Женщины & Мужчины & Женщины \\
\hline Муж & 52 & 39 & 42 & 32 \\
\hline Дети & 67 & 41 & 33 & 24 \\
\hline Высокий доход & 15 & 24 & 17 & 36 \\
\hline $\begin{array}{l}\text { Профессиональные достиже- } \\
\text { ния }\end{array}$ & 33 & 42 & 58 & 64 \\
\hline Общественное признание & 4 & 8 & 42 & 8 \\
\hline Затрудняюсь ответить & 19 & 17 & 8 & 12 \\
\hline
\end{tabular}


Еще одним основанием дифференциации восприятия образа успешной женщины выступают возрастные характеристики респондентов. Особенно значимые отличия в представлениях молодежи проявляются в группах женщин 18-24 лет и 25-29 лет (табл. 6). С возрастом меняются приоритеты в показателях успешности женщины: профессиональные достижения сменяются материнством.

Таблица 6. Признаки успешности женщины в представлении молодых мужчин и женщин различных возрастных групп, \%

\begin{tabular}{|l|c|c|c|c|}
\hline \multirow{2}{*}{$\begin{array}{c}\text { Признаки успешности жен- } \\
\text { шины }\end{array}$} & \multicolumn{2}{|c|}{$\mathbf{1 8 - 2 4}$ года } & \multicolumn{2}{c|}{ 25-29 лет } \\
\cline { 2 - 5 } Муж & Мужчины & Женщины & Мужчины & Женщины \\
\hline Дети & 50 & 35 & 60 & 29 \\
\hline Высокий доход & 61 & 34 & 50 & 57 \\
\hline $\begin{array}{l}\text { Профессиональные достиже- } \\
\text { ния }\end{array}$ & 14 & 26 & 10 & 29 \\
\hline Общественное признание & 19 & 53 & 40 & 38 \\
\hline Затрудняюсь ответить & 14 & 10 & 1 & 5 \\
\hline
\end{tabular}

\section{НЕОБХОДИМЫЕ КАЧЕСТВА СОВРЕМЕННОЙ ЖЕНЩИНЫ}

Приведенные выше данные показывают изменения гендерной идентичности, ослабление ее традиционной направленности. Рассмотрим представление молодежи о необходимых качествах современной женщины, являющихся важными компонентами гендерной идентичности.

В целях определения необходимых для современной женщины качеств и размещения соответствующего вопроса в анкете мы использовали метод неоконченных предложений ( $\mathrm{N}=80$ студентов). Предложение, которое предлагалось продолжить респондентам, выглядело следующим образом: «Современная женщина должна обладать такими качествами, как... (не более трех качеств)». В результате был получен список различных качеств, среди которых наиболее распространенными стали: ум, интеллект, целеустремленность, уверенность в себе, независимость, самодостаточность, верность, красота, привлекательность, ухоженность, женственность, семейственность, хозяйственность, хороший (легкий) характер, покладистость, искренность, скромность и др. Перечисленные характеристики назывались более одного раза представителями обоих полов, поэтому они и стали вариантами ответа соответствующего вопроса анкеты. Близкие по смыслу варианты были объединены: ум и интеллект; независимость и самодостаточность; красота, привлекательность, ухоженность (ее в основном отмечали женщины); хороший, 
легкий характер и покладистость. Ум / интеллект, целеустремленность, уверенность в себе и независимость / самодостаточность при обработке результатов были отнесены к маскулинным характеристикам гендерной идентичности, остальные - к фемининным.

Отметим, что проведенное исследование и в этом аспекте высветило гендерные отличия в восприятии основных необходимых качеств женщины. Большинство юношей и девушек отдали приоритет умственным способностям, которыми должна обладать женщина (в ответах девушек преобладали такие термины, как «ум», «образование», «сообразительность», «хитрость», юношей - «ум», «образование», «интеллектуальное развитие», «не должна быть глупой»). Девушки чаще всего использовали обозначенное выше качество в связке с целеустремленностью, тогда как юноши с одним из тех, которые мы отнесли к фемининным (женственность, привлекательность, скромность и т. д.). Т. е. первые два качества в ответах девушек в основном относились к маскулинным характеристикам гендерной идентичности, а в ответах юношей - одно к маскулинным, другое к фемининным. И только третьим качеством у представителей обоих полов чаще всего являлась фемининная характеристика.

Схожие данные были получены в ходе последующего анкетирования, позволившие более детально осветить проявляющуюся панораму. Наиболее важным качеством современной женщины, по мнению представителей обоих полов, является развитый ум и интеллект (так считают 49 \% мужчин и 53 \% женщин). Мнения противоположных полов относительно других качеств женщины значительно дифференцируются по гендерному основанию. Женщины в большей степени по сравнению с мужчинами приписывают к разряду ключевых необходимых качеств женщины такие, как целеустремленность 39 \%, уверенность в себе - 31 \%, независимость - 24 \%, которые ассоциируются с маскулинными характеристиками, а мужчины, наоборот, прежде всего выделяют фемининные качества женщины (рис. 1, 2). Расхождение мужских и женских оценок относительно маскулинных качеств женщины гораздо заметнее, нежели фемининных. Мужчины сохраняют традиционные стереотипы о женщине, в том числе и об ее основных гендерных характеристиках. Им непросто осознать и принять происходящие изменения гендерной идентичности женщины, которые проявляются в ее социальных статусах и ролях и связанных с ними личностных качествах. 


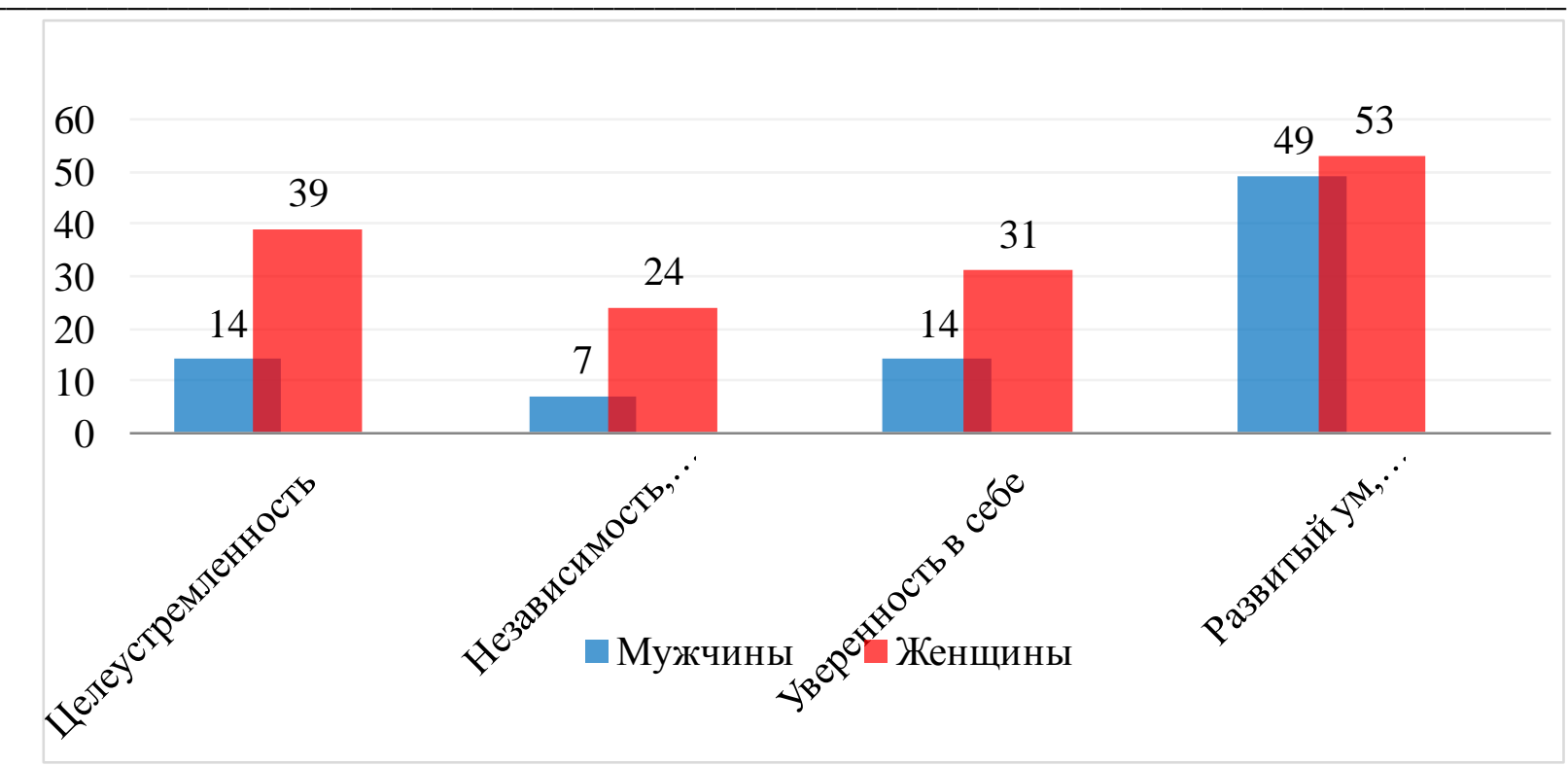

Рисунок 1. Представления мужчин и женщин о маскулинных характеристиках женщины, \%

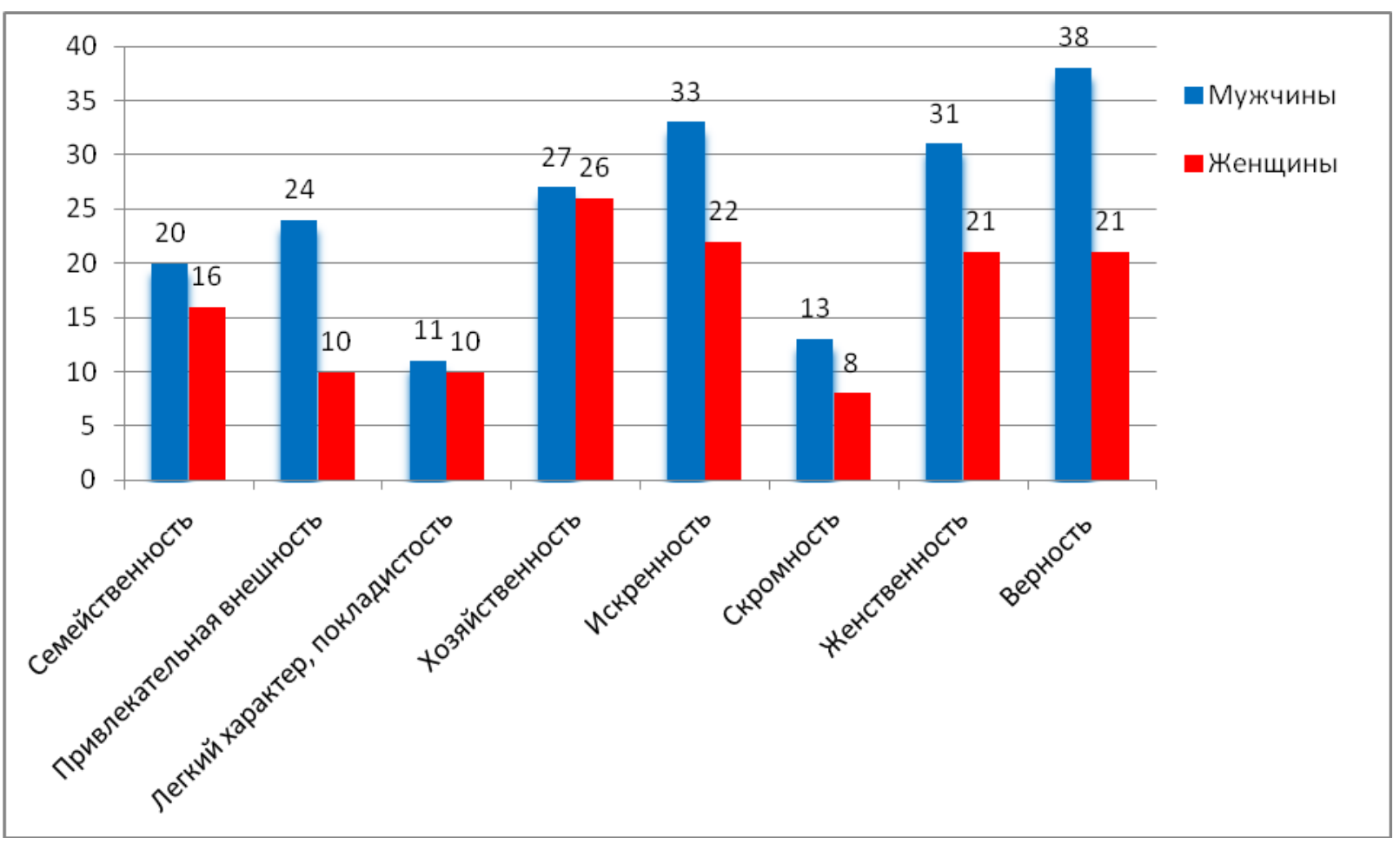

Рисунок 2. Представления мужчин и женщии о фемининных характеристиках женщины, \%

Отмечаемые изменения наблюдаются среди не только неверующих, но и религиозных женщин. Между этими группами хотя и существуют некоторые отличия в оценках, но они не носят принципиальный характер. Так, например, три наиболее важные качества женщины в этих группах одинаковые: развитые умственные способности (неверующие - $68 \%$, религиозные 
- $48 \%$ ), целеустремленность (44\% и $38 \%)$ и уверенность в себе (32\% и $31 \%)$.

Более выраженные различия между религиозными и неверующими молодыми людьми проявились в вопросе о существовании особого предназначения женщины. Если среди религиозной молодежи (без дифференциации по полу внутри этой группы, которая в данном случае выражена не существенно) $24 \%$ отвергают какое-либо особое предназначение женщины, тогда как $28 \%$ видят его в рождении и воспитании детей, то среди неверующих наблюдается совсем иное распределение - 55 \% и 13 \%. При этом неверующие молодые люди несколько чаще (17\% против $14 \%$ религиозных видят предназначение женщины в помощи мужчине и заботе о нем. В целом же среди мужчин (без дифференциации по религиозному признаку) 40 \% отвергают какое-либо особое предназначение женщины и только 20 \% видят его в рождении и воспитании детей, а среди женщин - 31 \% и 23 \%. Эти данные показывают размывание традиционных тезаурусных конструкций, которые на протяжении столетий подкреплялись религиозными догмами о ролях женщины, ключевые из которых были связаны с материнством. В тезаурусах молодого поколения все отчетливее прослеживается ослабление связи традиционных семейных ролей женщины с ее идентичностью.

\section{ЗАКЛЮЧЕНИЕ}

Проведенный эмпирический анализ восприятия московской молодежью жизненных приоритетов, ролей и гендерных характеристик женщины позволяет сделать несколько выводов, уточняющих некоторые аспекты данной проблематики в тезаурусном ключе. Во-первых, в тезаурусах молодых людей воспроизводятся как традиционные, так и либеральные представления о женщине, ее ролях и гендерных характеристиках, на основании которых формируется неопределенная гендерная идентичность женщины, включающая в себя трудно сочетаемые гендерные роли. Во-вторых, эти представления дифференцируются в зависимости от половозрастных и религиозных характеристик. Представления мужчин, особенно религиозных, о гендерных ролях женщины более традиционны, нежели женщин. Представления женщин с возрастом меняются и становятся больше ориентированными на семью и детей. В-третьих, религия является важным основанием поддержания традиционных ценностно-нормативных структур в тезаурусах молодежи, однако ей не удается блокировать проникновение либеральных идей. Во взглядах религиозных молодых людей хотя и более выражены традиционные элементы по сравнению с неверующими, однако также отмечается (особенно сильно это заметно среди женщин) высокая степень неопределенности гендерной идентичности женщины, сочетающей традиционные и либеральные гендер- 
ные роли. Тем самым происходит размывание традиционных представлений в различных группах молодежи, включая и религиозную, находя отражение в гендерной идентичности женщины, ее ролях и связанных с ними характеристиках.

\section{СПИСОК ЛИТЕРАТУРЫ}

Луков, В. А. (2018) Тезаурусная социология : в 4 т. : монография. М. : Изд-во Моск. гуманит. ун-та. Т. 1. 608 с.

Луков, В. А., Луков, Вл. А. (2008) Тезаурусы : Субъектная организация гуманитарного знания. М. : Изд-во Нац. ин-та бизнеса. 784 с.

Луков, В. А., Луков, Вл. А. (2013) Тезаурусы II : Тезаурусный подход к пониманию человека и его мира. М. : Изд-во Нац. ин-та бизнеса. 640 с.

Тихомиров, Д. А. (2015) Либерализация половой морали в современном мире // Знание. Понимание Умение. № 3. С. 93-108. DOI: $\underline{10.17805 / z p u .2015 .3 .8}$

Тихомиров, Д. А. (2017) Половая мораль московских студентов: религиозный аспект // Знание. Понимание. Умение. № 2. С. 210-220. DOI: 10.17805/zpu.2017.2.16

Дата поступления: 25.04.2018 г.

Тихомиров Дмитрий Андреевич - кандидат социологических наук, доцент кафедры политологии и социологии Российского экономического университета им. Г. В. Плеханова. Адрес: 117997, г. Москва, Стремянный пер., 28, корп. 1. Тел.: +7 (495) 958-23-27. Эл. адрес: dat1983@yandex.ru

Tikhomirov Dmitry Andreevich, Candidate of Sociology, Associate Professor, Department of Political Science and Sociology, Plekhanov Russian University of Economics. Postal address: Bldg. 1, 28 Stremyannaya Lane, 117997 Moscow, Russian Federation. Tel.: +7 (495) 958-23-27. E-mail: dat1983@yandex.ru

Новиџкая Ксения Владимировна - бакалавр социологии, магистрант факультета маркетинга Российского экономического университета им. Г. В Плеханова. Адрес: 117997, г. Москва, Стремянный пер., 28, корп. 1. Тел.: +7 (495) 958-23-27. Эл. адрес: vnovit@gmail.com

Novitskaya Kseniya Vladimirovna, Bachelor of Sociology, Graduate Student, Faculty of Marketing, Plekhanov Russian University of Economics. Postal address: Bldg. 1, 28 Stremyannaya Lane, 117997 Moscow, Russian Federation. Tel.: +7 (495) 958-23-27. E-mail: vnovit@gmail.com 
Для ичитирования:

Тихомиров Д. А., Новиџкая К. В. Представления молодежи Москвы о гендерных ролях и характеристиках современной женщины [Электронный pecypc] // Горизонты гуманитарного знания. 2018. № 3. С. 90-102. URL: http://journals.mosgu.ru/ggz/article/view/800 (дата обращения: дд.мм.гггг). DOI: 10.17805/ggz.2018.3.6 